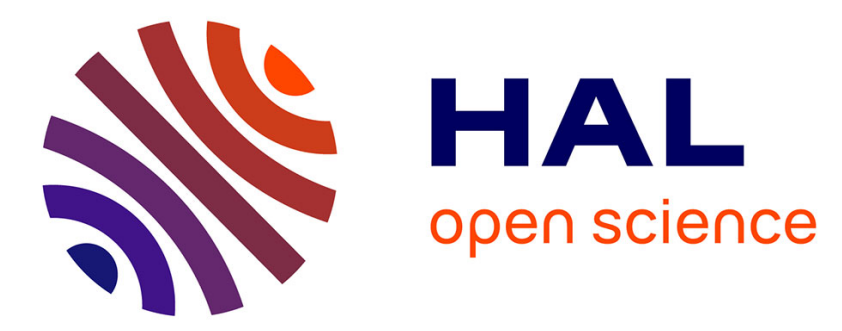

\title{
Fuel Cells prognostics using Echo State Network
}

Simon Morando, Samir Jemei, Rafael Gouriveau, Noureddine Zerhouni, Daniel Hissel

\section{To cite this version:}

Simon Morando, Samir Jemei, Rafael Gouriveau, Noureddine Zerhouni, Daniel Hissel. Fuel Cells prognostics using Echo State Network. Proceedings of the IECON 2013 - 39th Annual Conference of the IEEE Industrial Electronics Society, Jan 2013, Austria. pp.1630 - 1635. hal-00907631

\section{HAL Id: hal-00907631 \\ https://hal.science/hal-00907631}

Submitted on 26 Nov 2013

HAL is a multi-disciplinary open access archive for the deposit and dissemination of scientific research documents, whether they are published or not. The documents may come from teaching and research institutions in France or abroad, or from public or private research centers.
L'archive ouverte pluridisciplinaire HAL, est destinée au dépôt et à la diffusion de documents scientifiques de niveau recherche, publiés ou non, émanant des établissements d'enseignement et de recherche français ou étrangers, des laboratoires publics ou privés. 


\title{
Fuel Cells prognostics using Echo State Network
}

\author{
S. Morando ${ }^{1,2,3}$, S. Jemei ${ }^{1,2}$, R. Gouriveau ${ }^{2,3}$, N. Zerhouni ${ }^{2,3}$, D. Hissel ${ }^{1,2}$ \\ ${ }^{1}$ FEMTO-ST (UMR CNRS 6174) Energy department / University of Franche-Comté (UFC) \\ ${ }^{2}$ FC-LAB (FR CNRS 3539), Techn'Hom, 90010 Belfort Cedex, France \\ ${ }^{3}$ FEMTO-ST (UMR CNRS 6174) AS2M department / ENSMM
}

\begin{abstract}
One remaining technological bottleneck to develop industrial Fuel Cell (FC) applications resides in the system limited useful lifetime. Consequently, it is important to develop failure diagnostic and prognostic tools enabling the optimization of the FC. Among all the existing prognostics approaches, datamining methods such as artificial neural networks aim at estimating the process' behavior without huge knowledge about the underlying physical phenomena. Nevertheless, this kind of approach needs huge learning dataset. Also, the deployment of such an approach can be long (trial and error method), which represents a real problem for industrial applications where realtime complying algorithms must be developed. According to this, the aim of this paper is to study the application of a reservoir computing tool (the Echo State Network) as a prognostics system enabling the estimation of the Remaining Useful Life of a Proton Exchange Membrane Fuel Cell. Developments emphasize on the prediction of the mean voltage cells of a degrading FC. Accuracy and time consumption of the approach are studied, as well as sensitivity of several parameters of the ESN. Results appear to be very promising.
\end{abstract}

Keywords- Prognostics, Proton Exchange Membrane Fuel Cell, Reservoir Computing, Echo State Network, Multi-steps ahead Prediction

\section{INTRODUCTION}

Condition-Based Maintenance (CBM) can be seen as a set of activities that aims at performing maintenance actions at the right time when needed. CBM appears to be a promising strategy since it enables increasing the availability of a system while reducing costs. Consequently, this thematic benefits from a growing interest, and "prognostics" is becoming a major research framework [1], [2].

According to the literature, three classes of prognostics approaches are commonly distinguished [2]. 1) Model-Based prognostics aim at obtaining a physical model of the system's behavior [3]. This kind of approaches involves a high level of knowledge and supposes that the ageing process can be formalized into a mathematical form. 2) Experience-based prognostics rely on statistical treatments and aims at calculating the probability of a failure to occur at any time [4]. The applicability of this kind of approach is however dependent on the representativeness of past experiences that do not always reflect current conditions. 3) Data-driven prognostics aim at transforming real monitoring data into relevant indicators and trends that depict the health of a system [5], [6]. These approaches are a tradeoff between model-based and experience-based approaches. However, huge learning datasets are required in order to train artificial intelligence tools, which can lead to applicability problems: building a data- driven prognostics system can be time consuming, which impedes the transfer of such a technology to the industry. This is the problem addressed in this paper: how to go through a prognostics tool which is accurate enough to enable maintenance decision, and fast enough to be applicable in real world? More precisely, the aim of this paper is to study the application of a reservoir computing tool (the Echo State Network) as a prognostics system enabling the estimation of the Remaining Useful Life (RUL) of a Proton Exchange Membrane Fuel Cell (PEMFC).

The novelty consists in the use of an Echo State Network [7], [8] as a prognostics tool applied for low temperature fuel cells. An ESN is a neurons reservoir for which the learning step consists in a linear regression, keeping the same modeling capability of a Recurrent Neural Network (RNN) while saving the calculation time. Accuracy and complexity of the network are however dependent on some parameters that have to be well chosen. This aspect is discussed in the paper.

The paper is organized as follow. In a first part, data-driven prognostics is replaced within CBM strategy in order to define the limit of the study. Also, multi-steps ahead prediction strategies for this kind of prognostics approaches are defined. It enables formalizing the purpose of using ESN. In section III, the ESN tool is described. Mathematical backgrounds are given in order to define how the ESN can be used for prediction. Also, the problem of setting some parameters (reservoir design) is addressed. Before concluding, experiments are performed in order to discuss the usefulness of the ESN for prognostics purpose. Dataset used comes from experimental tests performed on a 20-cells PEMFC stack. The forecasts concern the mean cells voltage prediction, and the results appear to be promising

\section{DATA DRIVEN PROGNOSTICS - MATHEMATICAL FORMALIZATION}

\section{A. Towards fast and accurate data driven prognostics}

Condition-Based Maintenance (CBM) is an advanced maintenance system strategy improving reliability, security and costs of engineering systems. CBM architecture is used to be divided in seven layers / modules (Figure 1): 1) row data acquisition, 2) data processing (denoising, features extraction and selection), 3) condition assessment, 4) diagnostic, 5) prognostics, 6) decision making and 7) presentation of results. Therefore, the whole aspects of failure analysis and prediction should be viewed as a set of activities that all must be performed. Nevertheless, this paper focuses on prognostics of 
failures and only layers 1, 2 and 5 are addressed: data acquisition, signal processing and prognostics.

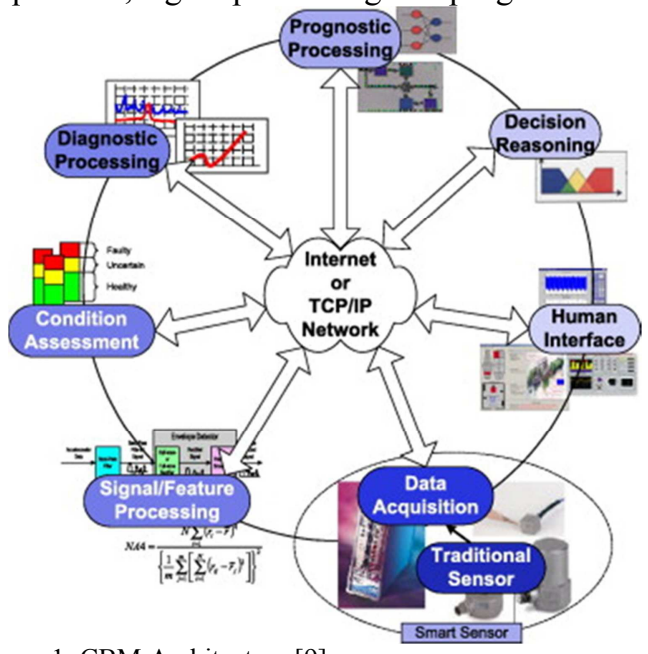

Figure 1: CBM Architecture [9]

In spite of some divergences in literature, prognostics can be defined as a process which objective is to estimate the Remaining Useful Life (RUL) of a system, i.e. the time before a failure occurs [10]. For that purpose, data-driven prognostics rely on the assumption that input-output data from the system are the major source of information to catch its behavior. Following that, these approaches are based on the real time exploitation of symptoms or indicators of degradations extracted from monitoring data (layers 1 and 2 of CBM architecture) which future evolution is determined by machine learning or data-mining approaches (see [11] for a taxonomy of useful approaches). From this point of view, data-driven prognostics approaches are very interesting since no prior on the behavior and no specific knowledge on the system's degradation are required. According to this, a particularly good trade-off between applicability and precision is reached. However, the learning time is one limit of this kind of application [12], as well as the need for sufficient learning datasets. This can be easily pointed out by considering prognostics based on Artificial Intelligence (AI) methods.

\section{B. Artificial Intelligence tools for prognostics}

Data-driven prognostics rely on the uses of an approximation tool from AI. This kind of system aims at approximating an input-output function. It can be seen as a black box model where the learning input and output target are known and the training phase consists in an optimization of the black box system parameters in order to fit the real function between the system input and output. Mathematically, it means that an input $X$ and a corresponding output $Y$ linked by the real function $\Gamma($.) can be written as:

$$
Y=\Gamma(X)
$$

And the estimation can be written as:

$$
\widehat{Y}=\widehat{\Gamma}(X)
$$

with $\hat{Y}$ the estimated output and $\hat{\Gamma}$ the approximated function obtained by a learning phase. In order to do that, $\hat{\Gamma}$ is expressed as a combination of a structure $f($.$) and a set of$ parameters $[\theta]$ [12], previously explained by using a learning algorithm $L a($.$) (as shown in equation 3$ ). It is easy to understand that the resulted error $\epsilon=Y-\hat{Y}$ must be as low as possible. This is the aim of the learning phase.

$$
\begin{aligned}
& \{f,[\theta]\} \leftarrow \operatorname{La}(X, Y) \\
& \widehat{\Gamma}(.)=f([\theta])
\end{aligned}
$$

Finally, the estimation can be formalized as in equation (4):

$$
\hat{Y}=f(X,[\theta])
$$

\section{Multi-steps prediction for prognostics}

A good designed maintenance system implies prediction at mid-term or long-term in order to schedule maintenance tasks. That's why a multi-step predictions system is necessary. According to [12], multi-step prediction can be divided in two main categories: prediction system designed with one output and prediction system designed for multiple outputs. In this article the Direct approach (Figure 3a) and the Parallel approach (Figure 3b) are considered.

a) Direct approach

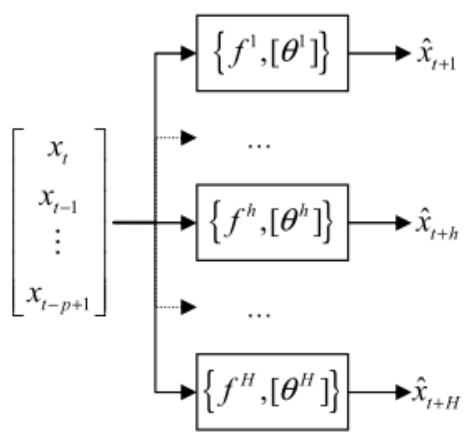

b) Parallel approach

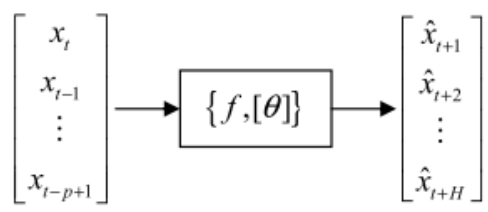

Figure 2: Representation of Direct and Parallel approach [12]

For the Direct approach, one model provides results for one forecasting horizon (called $h$ ). It means that the model does not provide forecasting values between $t$ and $t+h$. To solve this drawback, several models have to be built at the same time, as shown in figure $3 \mathrm{a}$ and in equation (5). It results in a longer algorithm duration.

$$
\begin{aligned}
& \hat{x}_{t+1}=f^{1}\left(x_{t}, x_{t-1}, \ldots, x_{t+1-p},\left[\theta^{1}\right]\right) \\
& \ldots \\
& \hat{x}_{t+h}=f^{h}\left(x_{t}, x_{t-1}, \ldots, x_{t+1-p},\left[\theta^{h}\right]\right) \\
& \ldots \\
& \hat{x}_{t+H}=f^{H}\left(x_{t}, x_{t-1}, \ldots, x_{t+1-p},\left[\theta^{H}\right]\right)
\end{aligned}
$$

Another method consists in the use of only one model providing results for several differents forecasting horizons such as discribed by the Parallel approach. It consists in a calculation of all forecasting steps between $t$ and $t+H$ with only one model, making the algorithm duration shorter than 
for the Direct approach. Equation (6) is the mathematical representation of the Parallel approach:

$$
\hat{X}_{t+1 \rightarrow t+H}=\left[\hat{x}_{t+1}, \ldots, \hat{x}_{t+H}\right]=f\left(x_{t}, \ldots, x_{t+1-p},[\theta]\right)
$$

with $\{f,[\theta]\}$ representing the model optimised to provide all the forecasting steps between $[1, \ldots, H]$ and $p$ is the number of regressors used.

An AI tool is choosen in order to fit the real function. In this paper, the AI tool choosed is the ESN thus the function $f^{h}$ represents the ESN and $[\theta]$ the main parameters of an ESN (detailed in the following part).

\section{ESN AS AN EFFICIENT PREDICTION SYSTEM}

\section{A. Backgrounds of ESN}

ESN is included into the Reservoir Computing (RC) scientific area, which is a specific Artificial Neural Network (ANN) architecture using a neurons reservoir enabling a better representation of human intelligence paradigm. Moreover, an ESN uses the parameter $\alpha$ called Echo State Property (ESP) that makes the reservoir dynamic. This kind of neural networks was introduced by Jaeger works about ESN in 2001 [7], [8]. However, the term of RC appeared only in 2006 after the creation of others "reservoir" neural network architectures such as liquid-state machines [13] and BackPropagationDecorrelation networks [14].

An ESN (Figure 3) consists in a large number of neurons located in a so-called "reservoir", with a randomly (and fixed) connectivity between each other. The reservoir (called $\mathrm{W}_{\text {res }}$ ) and several weights matrix (detailed as following) are defined. The Input-Reservoir weight matrix, called $\mathrm{W}_{\text {inp }}$, is created randomly and also fixed. It makes the link between the input of the network and the reservoir. The Reservoir-Output weight matrix is called $\mathrm{W}_{\text {out }}$ and makes the link between the reservoir and the output. Those elements are the main components for a basic use of ESN. This model can be improved by adding another optional matrix, named $\mathrm{W}_{\text {feed, }}$ which represents the retroaction of the outputs. To summarise, for the basic structure, there are two fixed matrix, $\mathrm{W}_{\text {inp }}$ and $\mathrm{W}_{\text {res }}$, and only $\mathrm{W}_{\text {out }}$ has to be trained. Consequently the training consists in a very simple linear regression. It is one of the main advantages of the ESN: the training duration. The ESN application domains are various. They can be founded in medical [15], economic [16] and optical applications [17].

\section{B. Mathematical formulation and learning scheme}

The first step is to design the reservoir (detailed in part C) and then the calculation to optimize the network can start. This step begins with the reservoir output calculation for the training sequence. The update of the reservoir is calculated as following [18]:

$$
\tilde{x}(n)=f\left(W_{i n p} \cdot u(n)+W_{\text {res }} \cdot x(n-1)\right)
$$

where $\tilde{x}$ is the update of the reservoir, $u(n)$ the input of the ESN and $x(n-1)$ is the previous output of the reservoir.

Then it is possible to calculate the reservoir output $\mathrm{x}(\mathrm{n})$ by using the echo state property $\alpha$ :

$$
x(n)=(1-\alpha) \cdot x(n-1)+\alpha \cdot \tilde{x}(n)
$$

This calculation makes it possible to calculate the network output as shown in equation (9):

$$
\left.y(n)=W_{\text {out }} \cdot x(n)+W_{\text {feed }} \cdot y(n-1)\right)
$$

Nevertheless the $\mathrm{W}_{\text {feed }}$ matrix is optional thus the output formula for a basic structure $\mathrm{ESN}$ is:

$$
y(n)=f\left(W_{\text {out }} \cdot x(n)\right)
$$

The learning algorithm consists in reducing the Mean Square Error (MSE) between the computed values for the training data set $\mathrm{y}_{\text {predicted }}$ and the targets $\mathrm{y}_{\text {target }}$ :

$$
M S E=\frac{1}{N} \cdot \sum_{1}^{N}\left(y_{\text {target }}(n)-y_{\text {predicted }}(n)\right)^{2}
$$

Also equivalent to:

$$
M S E=\frac{1}{N} \cdot \sum_{1}^{N}\left(y_{\text {target }}(n)-f\left(W_{\text {out }} \cdot x(n)\right)\right)^{2}
$$

Where $\mathrm{N}$ is the number of dismissed samples, due to the initial condition of the different matrix. The goal is now to find the best $\mathrm{W}_{\text {out }}$ weights matrix corresponding to the lowest MSE possible result, achieved by a linear regression.

\section{Reservoir design}

The design of the ESN reservoir consists in the configuration of several parameters:

- The number of reservoir neurons $\mathrm{N}_{\text {res }}$ :

The number of reservoir neurons is one of the most important parameters. To find a better linear combination of the signals in order to find the best target, it is better to define a large reservoir (it is not uncommon to find a reservoir containing more than $10^{4}$ neurons [19]).

- The reservoir connectivity c:

To obtain best results, the reservoir neurons are not all connected. For this reason, a connectivity parameter has to be designed. It represents the percentage of non-zero weights in the reservoir and can take values between 0 and 1. For example, the following matrix in Table 1 , with a connectivity $c=0.25$ (i.e. $1 / 4$ of connections have non-zero values) represents the links between neurons. As we can see, the output of neuron \#1 is linked to the input of neuron \#2 by a weight of 0.58 .

Table 1: Example of a reservoir matrix (4 neurons)

\begin{tabular}{|l|l|l|l|l|}
\hline & 1 & 2 & 3 & 4 \\
\hline 1 & 0 & $\mathbf{0 . 5 8}$ & 0 & 0 \\
\hline 2 & 0 & 0 & 0 & 0 \\
\hline 3 & 0 & 0.75 & 0 & 0.25 \\
\hline 4 & 0.22 & 0 & 0 & 0 \\
\hline
\end{tabular}

- The spectral radius

Mathematically, the spectral radius of a square matrix corresponds to the maximum value of this matrix eigenvalues. In ESN, the spectral radius is used to scale the non-zero elements of $\mathrm{W}_{\text {res. }}$. The principle is to create the $\mathrm{W}_{\text {res }}$ matrix randomly with a connectivity parameter, and calculate the spectral radius of the matrix created. Then, the $\mathrm{W}_{\text {res }}$ matrix is divided by the spectral radius previously calculated. Hence, the result of this division gives a matrix with a spectral radius 
of 1 . The last step consists in the multiplication of this matrix by the spectral radius chosen by the user. The $\mathrm{W}_{\text {res }}$ matrix is | now created with the desired scaling.

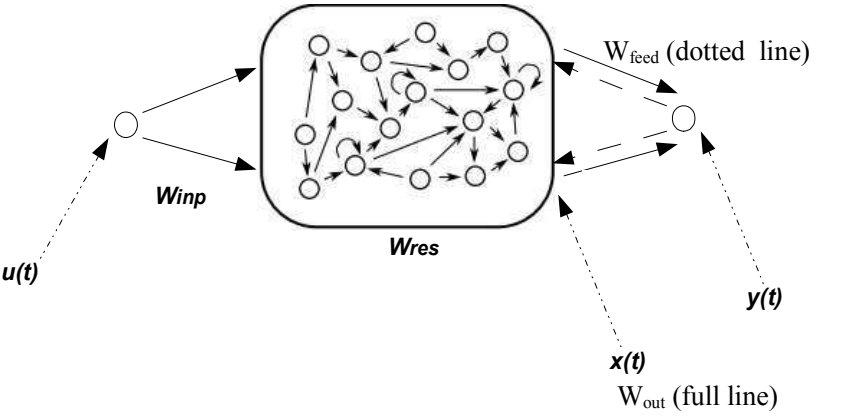

Figure 3: Basic Structure of an Echo State Network [20]

- The leaking rate $\alpha$ :

This parameter is also called ESP. It is an important notion of ESN and it corresponds to the previous reservoir output importance, as shown in equation 8. Its value has to be determined in the range [0;1], and the more important this value is, the less important becomes the reservoir echo.

\section{EXPERIMENTS: FC VOLTAGE PREDICTION CONSIDERING AN AGEING PROCESS}

\section{A. Data set}

The data set used for simulations comes from a 1000 hours PEMFC duration test realized at the FCLAB research institute [21], [22]. Figure 4 represents the evolution of the experimental cells mean voltage (one sample represent 30 seconds). The data were perturbed by the Electrochemical Impedance Spectrometry (EIS) characterization at different times as shown in Figure 4a at the sample 110000 for example.

In order to predict some values, the data have to be processed (for example it can be judicious to delete the perturbations due to the EIS characterizations). The method considered here is to delete the abnormal points manually and then use a moving average filter in order to reduce the signal noise (Figure $4 \mathrm{~b}$ ).

\section{B. Simulation settings}

This paper uses the Direct and Parallel forecast approach [12], consequently the purpose is to use the mean voltage cells $U_{\text {moy }}$ (n) to create three regressors (in equation 5) as input of ESN in order to predict $\mathrm{U}_{\text {moy }}(\mathrm{n}+500), \mathrm{U}_{\text {moy }}(\mathrm{n}+1000)$ and $\mathrm{U}_{\text {moy }}(\mathrm{n}+2500)$.

The data (after the above mentioned pre-treatment) are used as input of an ESN. The 10000 first values are used to train the network and the remaining values to test it. The metrics used to check the network performance are the following.

-Root Mean Square Error (RMSE), sometimes called Root Mean Square Deviation (RMSD), is commonly used to quantify the difference between a forecasted signal and its real target.
$R M S E=\sqrt{\frac{\sum_{t=1}^{n}\left(y_{t}-\hat{y}_{t}\right)^{2}}{n}}$

-Mean Average Percentage Error (MAPE) is also a quantification measurement between two signals. The main difference is the result of this calculation which is a percentage.

$M A P E=\frac{1}{n} \sum_{t=1}^{n}\left|\frac{\hat{y}_{t}-y_{t}}{\hat{y}_{t}}\right|$

-The Coefficient of determination $\left(\mathrm{R}^{2}\right)$ is a value between 0 and 1 letting a quick evaluation of a prognostics performance. The more nearest to 1 this value is, the better is the prediction.

$$
R^{2}=1-\frac{\left(\sum \hat{y}_{t}-y_{t}\right)^{2}}{\left(\sum y_{t}-y_{m o y}\right)^{2}}
$$

-The simulation duration (in seconds). That is an important parameter for real time industrial applications. These simulations have been realized with a computer equipped with a Intel ${ }^{\circledR}-$ Core $^{\mathrm{TM}} \mathrm{i} 5-3210 \mathrm{M}$ CPU of $2.5 \mathrm{Ghz}$ and 6 Go of RAM memory.

Each simulation corresponds to a couple of parameters: $\alpha$ (taking the values $0,2 / 0,5 / 0,7$ ) and $\mathrm{N}_{\text {res }}$ (equal to 50 and 250 neurons) .

\section{Results and discussion}

As shown in Table 2, the results have low error (RMSE and MAPE) for every tested couple of $\alpha$ and $\mathrm{N}_{\text {res }}$. However, best results are observed for 50 neurons and $\alpha<0.5$. That means than the $(t-1)$ reservoir output value is important for the calculation of the reservoir at the moment $(t)$. That can be explained by the global shape of the studied characteristic (mean voltage of the fuel cell stack), where just one sharp variation near sample 125000 can be seen.

a. Row data
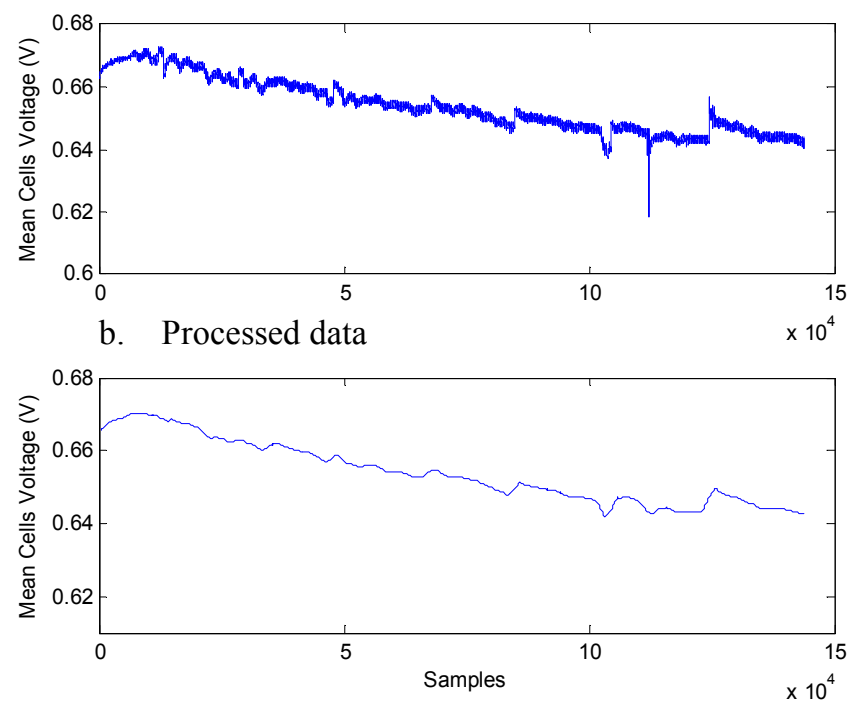

Figure 4: Mean cells voltage time evolution before (a) and after data processing (b) 
Table 2: Performance summary of ESN using a Direct structure

\begin{tabular}{|c|c|c|c|c|c|c|}
\hline & \multicolumn{6}{|c|}{ Alpha $=0,2$} \\
\hline & \multicolumn{3}{|c|}{$\mathrm{N}=50$} & \multicolumn{3}{|c|}{$\mathrm{N}=250$} \\
\hline & $\mathrm{h}=500$ & $\mathrm{~h}=1000$ & $\mathrm{~h}=2500$ & $\mathrm{~h}=500$ & $\mathrm{~h}=1000$ & $\mathrm{~h}=2500$ \\
\hline RMSE & 0,0002 & 0,0006 & 0,0018 & 0,0002 & 0,0006 & 0,0018 \\
\hline MAPE & 0,0205 & 0,068 & 0,2263 & 0,0204 & 0,068 & 0,2273 \\
\hline \multirow[t]{4}{*}{$\mathrm{R}^{2}$} & 0,9968 & 0,9756 & 0,7674 & 0,9968 & 0,9756 & 0,7658 \\
\hline & \multicolumn{6}{|c|}{ Alpha $=0,5$} \\
\hline & \multicolumn{3}{|c|}{$\mathrm{N}=50$} & \multicolumn{3}{|c|}{$\mathrm{N}=250$} \\
\hline & $\mathrm{h}=500$ & $\mathrm{~h}=1000$ & $\mathrm{~h}=2500$ & $\mathrm{~h}=500$ & $\mathrm{~h}=1000$ & $\mathrm{~h}=2500$ \\
\hline RMSE & 0,0002 & 0,0006 & 0,002 & 0,0002 & 0,0006 & 0,0021 \\
\hline MAPE & 0,0195 & 0,068 & 0,2412 & 0,0204 & 0,068 & 0,2494 \\
\hline \multirow[t]{4}{*}{$\mathrm{R}^{2}$} & 0,9969 & 0,9748 & 0,7111 & 0,9966 & 0,9747 & 0,6796 \\
\hline & \multicolumn{6}{|c|}{ Alpha $=0,7$} \\
\hline & \multicolumn{3}{|c|}{$\mathrm{N}=50$} & \multicolumn{3}{|c|}{$\mathrm{N}=250$} \\
\hline & $\mathrm{h}=500$ & $\mathrm{~h}=1000$ & $\mathrm{~h}=2500$ & $\mathrm{~h}=500$ & $\mathrm{~h}=1000$ & $\mathrm{~h}=2500$ \\
\hline RMSE & 0,0002 & 0,0006 & 0,0021 & 0,0002 & 0,0006 & 0,0021 \\
\hline MAPE & 0,0202 & 0,068 & 0,2501 & 0,0202 & 0,068 & 0,2514 \\
\hline $\mathrm{R}^{2}$ & 0,9967 & 0,9748 & 0,6772 & 0,9966 & 0,9746 & 0,6733 \\
\hline
\end{tabular}

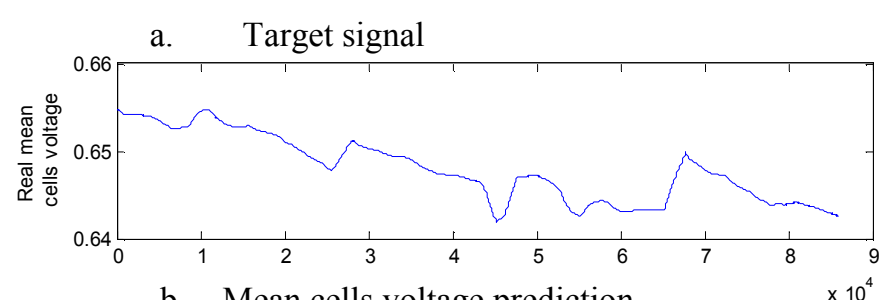

b. Mean cells voltage prediction
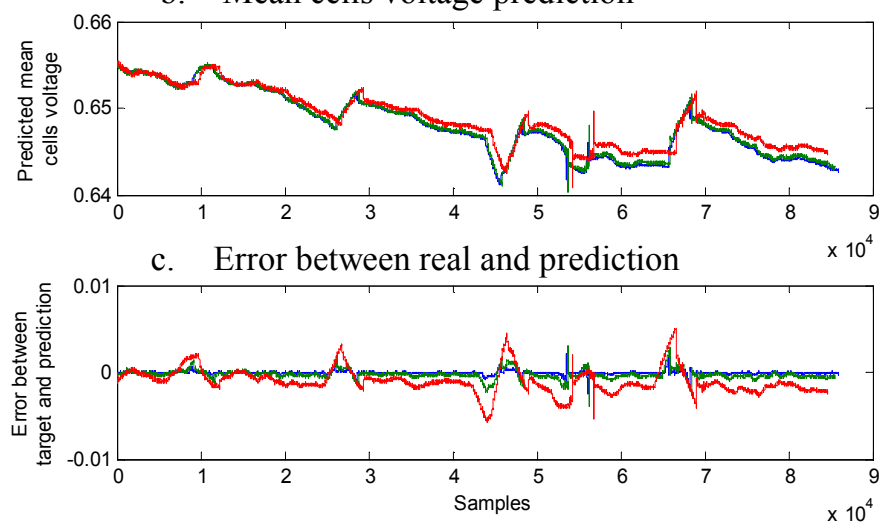

Figure 5: Test Target (a) and Direct predicted mean cells voltage (b) in blue for $\mathrm{h}=500$, in green for $\mathrm{h}=1000$ and in red for $\mathrm{h}=2500$ samples and Error between real and prediction (c)

Figure 5 represents the target (in a) and the predicted output of the ESN (in b) for $\alpha=0.5$ and $\mathrm{N}_{\text {res }}=50$. It is also important to underline the fact than the first 100 points were forgotten. These points are not precise due to the initialization phase of the reservoir. Once the reservoir is set, the prediction becomes really good. Figure 5c shows the error between the target and the predicted signal, where the maximal error corresponds in the more sharp variation of the mean cells voltages (generally after an EIS characterisation). However, these results cannot be dissociated from the simulation duration. In Table 3 , the evolution of time simulation is not a linear function dependant on the number of neurons. Generally, the more neurons there are in the reservoir, the better are the results but longer is the simulation time. Nevertheless, in any application, the number of neurons has to be previously designed to really correspond to the desired application.

Figure 6 shows Parallel structure test results, with nearly the same accuracy than the Direct structure even if the Direct structure results remain the bests in term of accuracy. However, in a Direct structure, the information between $t$ and $t+h$ is missing whereas those information are sometimes interesting. For example, to obtain the informations between $t$ and $t+1000,1000$ ESN have to be created and simulated. As shown in Table 3, one ESN simulation using Direct approach lasts about 19 seconds with $\mathrm{N}=50$ and $\alpha=0.5$ thus the totallity of the 1000 ESN simulations lasts 19000 seconds whereas for the Parallel structure, with the same values for $\mathrm{N}$ and $\alpha$, the simulation for $t+1000$ lasts only 185 seconds. Consequently the structure choice depends on the system application. In a fuel cell system, even if the results of Direct approach are quite good, a Parallel approach is more interesting due to the need of ageing information between $t$ and $t+h$.
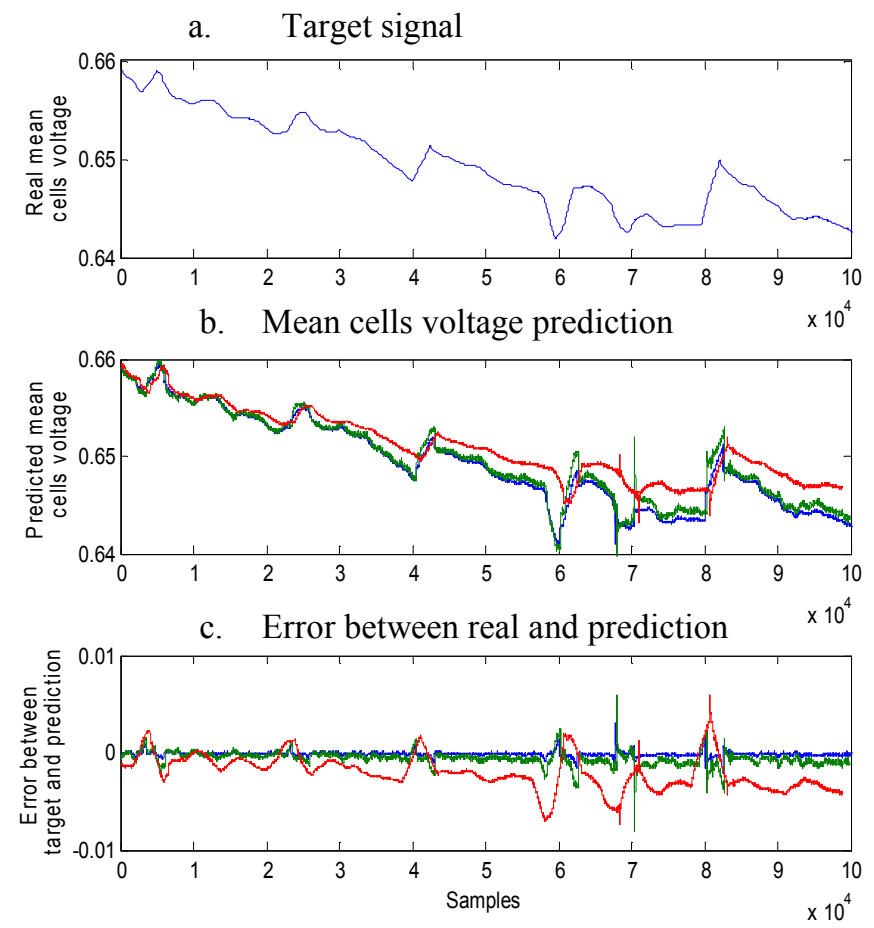

Figure 6: Test Target (a) and Parallel predicted mean cells voltage (b) in blue for $\mathrm{h}=500$, in green for $\mathrm{h}=1000$ and in red for $\mathrm{h}=2500$ samples and Error between real and prediction (c) 
Table 3: ESN Direct approach simulations durations (in seconds)

\begin{tabular}{|c|c|c|c|c|c|c|}
\cline { 2 - 7 } \multicolumn{1}{c|}{} & \multicolumn{3}{c|}{$\mathrm{N}=50$} & \multicolumn{3}{c|}{$\mathrm{N}=250$} \\
\cline { 2 - 7 } \multicolumn{1}{c|}{} & $\mathrm{h}=500$ & $\mathrm{~h}=1000$ & $\mathrm{~h}=2500$ & $\mathrm{~h}=500$ & $\mathrm{~h}=1000$ & $\mathrm{~h}=2500$ \\
\hline $\begin{array}{c}\text { Alpha }= \\
0,2\end{array}$ & 19 & 18,95 & 18,8 & 27,96 & 27,4 & 27,94 \\
\hline $\begin{array}{c}\text { Alpha } \\
0,5\end{array}$ & 19,31 & 19 & 21,49 & 27,6 & 27,89 & 26,94 \\
\hline $\begin{array}{c}\text { Alpha }= \\
0,8\end{array}$ & 19,1 & 19,53 & 18,87 & 27,18 & 27,35 & 26,96 \\
\hline
\end{tabular}

\section{CONCLUSION}

It is important to underline that this article and these simulations do not improve the ESN theory and fuel cells systems; it is just a proposition of a new concept to apply PHM with a data driven method (here with ESN) to a PEMFC system in order to predict the degradation evolution of the stack.

First, this article shows that the ESN is a powerful AI tool that can be used for PHM purpose. The first results are very promising and in the future it would be also interesting to develop full data-driven models using this tool. Nevertheless, the parameters and the design of ESN have to be optimized for each application and other forecasting approaches than Direct and Parallel have to be studied, such as the Iterative approach. Secondly, the fuel cell systems degradation can be surely forecasted. In this paper, only the mean cell voltage has been used. As perspectives, other parameters coming from measurement on an actual PEMFC system could also been considered, and the health assessment and an estimation of the RUL of the system will be realized.

\section{ACKNOWLEDGMENT}

The used of COCONPAC (project funded by the CNRS) experiment data were greatly appreciated. This study has been realized thanks to the region of Franche-Comté funds.

\section{REFERENCES}

[1] A. Heng, S. Zhang, A. C. C. Tan, et J. Mathew, « Rotating machinery prognostics: State of the art, challenges and opportunities ", Mechanical Systems and Signal Processing, vol. 23, no 3, 2009, pp. 724-739.

[2] A. K. S. Jardine, D. Lin, et D. Banjevic, « A review on machinery diagnostics and prognostics implementing condition-based maintenance », Mechanical Systems and Signal Processing, vol. 20, no 7, 2006, pp. $1483-1510$

[3] C. S. Byington, M. Watson, M. J. Roemer, T. R. Galic, et J. J. McGroarty, " Prognostic enhancements to gas turbine diagnostic systems », in 2003 IEEE Aerospace Conference, 2003. Proceedings, vol. 7, 2003, pp. 3247-3255.

[4] Wang W, "A model to predict the residual life of rolling element bearings given monitored condition information to date", IMA J of Manag, vol.13, 2002, pp. 3-16.
[5] M. Karpenko et N. Sepehri, « A neural network based fault detection and identification scheme for pneumatic process control valves », in 2001 IEEE International Conference on Systems, Man, and Cybernetics, vol. 1, 2001, pp. 93-98.

[6] Wang W, "An adaptative predictor for dynamic system forecasting", Mechanical Systems and Signal Processing, vol.21, 2007, pp.809-823.

[7] H. Jaeger, "The "echo state" approach to analysing and training recurrent neural networks", Technical Report GMD 148, German National Research Center for Information Technology, 2001.

[8] Jaeger, H. Tutorial on training recurrent neural networks, covering BPPT, RTRL, EKF and the echo state network approach. Technical report. GMD-German National Research Institute for Computer Science, 2002.

[9] M. Lebold et M. Thurston, «Open standards for Condition-Based Maintenance and Prognostic Systems », presented at the 5th Annual Maintenance and Reliability Conference, 2001.

[10] ISO13381-1, Condition monitoring and diagnostics of machines prognostics - Part1: General guidelines. International Standard, ISO, 2004.

[11] C. Byington, M. Roemer, M. Watson, T. Galie, and C. Savage, "Prognostic enhancementsto diagnostic systems (PEDS) applied to shipboard power generationsystems", In ASME/IGTI Turbo ExpoPower for Land, Sea, and Air, Vienna, Austria, 2004.

[12] R. Gouriveau et N. Zerhouni, «Connexionist-Systems-Based Long Term Prediction Approaches for Prognostics », IEEE Transactions on Reliability, vol. 61, no 4, 2012, pp. 909-920.

[13] W. Maass, T. Natschlager and H. Markram, "Real-time computing without stable states : A new frame-work for neural computation based on perturbations", Neural Compututations, vol.14, 2002, pp. 2531-2560.

[14] J. J. Steil, "Backpropagation-decorrelation, Online recurrent learning with $\mathrm{O}(\mathrm{N})$ complexity", Proceedings of the International Joint Conference on Neural Networks, vol. 2, 2004, pp. 843-848.

[15] F. Ongenae, S. Van Looy, D. Verstraeten, T. Verplancke, D. Benoit,F. De Turck, T. Dhaene, B. Schrauwen, J. Decruyenaere, "Time series classification for the prediction of dialysis in critically ill patients using echo statenetworks", Engineering Applications of Artificial Intelligence, vol. 26, 2013, pp. 984-996.

[16] Xiaowei Lin, Zehong Yang, Yixu Song, "Intelligent stock trading system based on improved technical analysis and Echo State Network", Expert Systems with Applications, vol. 38, no 9, 2001, pp. 1134711354.

[17] L. Larger et J. M. Dudley, « Nonlinear dynamics: Optoelectronic chaos », Nature, vol. 465, no 7294, 2010, pp. 41-42.

[18] Lukoševičius, M., "A practical guide to applying echo state networks", Neural Networks: Tricks of the Trade, vol. 7700, 2012, pp. 659-686.

[19] F. Triefenbach, A. Jalalvand, B. Schrauwen, et J.-P. Martens, « Phoneme recognition with large hierarchical reservoirs », in Advances in Neural Information Processing Systems, vol. 23, 2010, pp. 2307-2316.

[20] I. B. Yildiz, H. Jaeger, et S. J. Kiebel, « Re-visiting the echo state property », Neural Networks, vol. 35, 2012, pp. 1-9.

[21] Wahdame B., Girardot L., Hissel D., Harel F., François X., Candusso D., Pera M.-C., Dumercy L., "Impact of power converter current ripple on the durability of a fuel cell stack", In International Symposium on Industrial Electronics, France, 2008.

[22] Gérard M., Poirot-Crouvezier J.-P., Hissel D., Pera M.-C., "Ripple Current Effects on PEMFC Ageing Test by Experimental and Modeling", In ASME 8th International Fuel cell science, Engineering and Technology Conference, New York, USA, 2010. 